\title{
Grain dust and respiratory health in South African milling workers
}

\author{
Max Bachmann, Jonathan E Myers
}

\begin{abstract}
Respiratory health was investigated in 224 grain milling workers. The likelihood of respiratory symptoms and chronic airflow limitation was raised for workers exposed to dust independent of the effects of smoking. Smokers were more likely than non-smokers to respond to a bronchodilator at the end of the working week. Dust was more strongly associated with most abnormal outcomes than was smoking. Subjective categories of exposure to dust were more strongly associated with most abnormal outcomes than were objective categories. The prevalence of all symptoms at the time of a survey conducted at the mill six years before was higher in workers who subsequently left the mill than in those who remained employed although the differences were not significant.
\end{abstract}

Cross sectional epidemiological studies have shown a higher prevalence of respiratory symptoms and acute and chronic airway obstruction among grain handlers than among workers not exposed to grain dust, controlling for the effects of smoking. ${ }^{1-4}$ External reference groups, usually of civic workers, have most commonly been used for comparisons. Few studies have compared workers exposed to different dust concentrations within the same workplace. ${ }^{45}$

Few longitudinal studies have been conducted. Chan-Yeung, Tabona, Enarson, and colleagues have studied a cohort of grain elevator workers over six years, reporting greater declines in forced expiratory volume in one second $\left(\mathrm{FEV}_{1}\right)$ among grain handlers older than 50 compared with controls in the same age group $^{6}$; that the rate of $\mathrm{FEV}_{1}$ decline over six years correlated with across shift decrease in $\mathrm{FEV}_{1}$ at initial assessment suggesting that asthma can lead to chronic airflow limitation ${ }^{7}$; and that the likelihood of a rapid decline in FEV 1 over six years was increased

Industrial Health Research Group, Department of Sociology, University of Cape Town, South Africa M Bachmann

Department of Community Health, University of Cape Town, South Africa

J E Myers with exposure to high dust levels. ${ }^{8}$ Another longitudinal study did not show an excessive decline in lung function among grain workers compared with controls, but did show a higher prevalence of symptoms in workers who subsequently left employment than among those who did not. This suggested that workers with respiratory symptoms were more likely to leave their jobs in future than workers without symptoms. ${ }^{9}$ Broder et al have also reported an increased prevalence of symptoms among new grain workers after an initial two and a half months of employment. On the other hand workers who had been employed for at least nine years had fewer symptoms and showed no such increase. ${ }^{10}$ It is plausible that symptomatic new workers would leave grain work early.

Respiratory epidemiological research can assist in planning and motivating dust and smoking control programmes. Occupational health in the South African grain milling industry is particularly amenable to influence at present, as new mills are being built and new machinery installed while respiratory surveillance is being introduced increasingly. ${ }^{11}$

This report describes the findings of a follow up respiratory survey conducted among workers exposed to different concentrations of grain dust in Cape Town, South Africa. The objectives were to perform a cross sectional study of the respiratory health of grain workers, and to conduct a longitudinal analysis of a subgroup surveyed in 1983. In particular it was of interest to see if the healthy worker effect operated in this workforce. Other aims were to measure dust objectively, and to investigate the relations between workers' perceptions of their exposure to dust and more objective methods of assessment of exposure.

\section{Material and methods}

Our study was a repeat measures design including a cohort. Between August and November 1983, 582 workers at four grain mills and 153 workers at a packaging factory in Cape Town, South Africa, participated in a cross sectional survey. ${ }^{4}$ Workers at one of the mills were surveyed again during February and March, 1989. Two hundred and twenty four workers, including all production workers at the mill 
at the time of the survey, were included in this study. Of the 154 workers from this mill who had been studied in $1983,102(67 \%)$ were still present at the mill in 1989 . Workers were mainly exposed to various forms of wheat, ranging from raw grain to fine flour, as well as various biological and chemical contaminants.

As in the 1983 study, all subjects answered questions about previous employment, degrees of exposure to dust and tobacco smoke, acute and chronic respiratory symptoms, and previous illnesses. The questionnaire was based on that of the American Thoracic Society (ATS) ${ }^{12}$ modified slightly for South African conditions. ${ }^{4}$ Each subject was interviewed in English or Xhosa by one of two trained interviewers.

All subjects performed spirometry three times: (1) early on Monday mornings after two days without exposure to grain dust, before starting work for the week, (2) towards the end of the Thursday afternoon shift of the same week as the initial test after four shifts at work, and (3) again on Thursdays at least five minutes after two inhalations of a bronchodilator (rimiterol) from a self administered pump. It was only possible to repeat spirometry on Thursdays for 204 subjects $(91.5 \%$ total $)$ as 20 workers tested on Mondays were not at work on the respective Thursdays, for a variety of reasons.

Spirometry was conducted with two Vitallograph $S$ model bellows volume-time spirometers with the procedures recommended by the ATS. ${ }^{13}$ It was not possible to use the same spirometer (Autospiror HI298) that had been used in the previous survey, as it had been damaged. Spirometry was performed in a sitting position without nose clips. Tests were supervised by three trained technicians, and quality control was strict. Test reproducibility was used as a guide to whether further attempts were necessary. Even when good reproducibility could not be obtained after at least five blows, however, results were included if the traces were acceptable ${ }^{13}$ so as not to exclude those subjects whose poor lung function impaired consistency. ${ }^{14}$ The maximum forced vital capacity (FVC) and $\mathrm{FEV}_{1}$ for each procedure were recorded.

Spirometers were calibrated twice daily with a 31 syringe and did not require adjustment as both spirometers gave identical accurate readings. Start of exhalation was determined by back extrapolation, ${ }^{13}$ which has been shown to bring such spirometers into compliance with ATS criteria. ${ }^{15}$ Where exhalation continued after the end of the chart had been reached, forced vital capacity was read from the maximum excursion of the spirometer stylus. The technicians watched each procedure to detect fluctuation of the stylus in the case of nose breathing and it was not necessary to reject any traces for this reason. Lung volumes obtained by spirometry were adjusted to body temperature and pressure according to the average temperature and pressure for each session. ${ }^{16}$

Because of the racial heterogeneity of the study population and uncertainty about suitable prediction values for different ethnic groups ${ }^{17}$ observed lung functions were not compared with predicted values. Instead, relative values for each subject were obtained by expressing: (1) $\mathrm{FEV}_{1}$ on Monday as a percentage of FVC on Monday, (2) change in FEV from Monday to Thursday as a percentage of the Monday value, and (3) change in $\mathrm{FEV}_{1}$ after bronchodilator on Thursday as a percentage of the $\mathrm{FEV}_{1}$ before bronchodilator. These relative values are appropriate for the investigation of chronic airflow limitation and acute airway obstruction although restrictive changes may be missed.

All participants were asked to characterise their work as (1) not dusty, (2) slightly dusty or dusty, and (3) very dusty, providing a subjective categorisation of dust exposure as low, medium, or high.

To derive a more objective estimate of exposure to dust for each subject, workers performing similar tasks were grouped into seven exposure zones based on the authors' previous observation of the mill. ${ }^{18}$ Exposure zones were then grouped into low, medium, and high dust exposure categories. Sample sizes for each exposure zone were chosen so as to give $90 \%$ confidence of including at least one worker from the subgroup with the highest $20 \%$ of dust exposures in each zone. ${ }^{19} \mathrm{~A}$ total sample of 50 measurements was obtained over five days in December 1989. No major changes in the production process had occurred between 1983 and 1989. Differences in exposure between the time of the dust and respiratory surveys are unlikely as both were conducted in the same season. A dust survey conducted by one of us in the same mill two years previously showed similar dust exposures; the two dust surveys could not be combined for serial exposure estimation as the initial study did not use the same sampling strategy.

Exposure to total dust was measured gravimetrically after full shift personal sampling with SKC and DuPont personal dosimeters. Dosimeters were calibrated daily to flow at approximately 1.81 a second; flow rates were measured at the beginning and end of each shift. Cellulose filters of $37 \mathrm{~mm}$ diameter were used. Filters were weighed after 24 hours of dessication before and 24 hours of dessication after each period of sampling. Average dust concentrations were calculated from the increases in filter mass and rates and durations of air flow..$^{20}$

The dust concentrations obtained confirmed the authors' previous grouping of exposure zones into low, medium, and high objective dust categories. The mean concentration in each zone was rounded off to the nearest whole number to give a dust score. The number of years worked in each of the current and two previous jobs was multiplied by the dust scores for the respective jobs; the sum of these products 
Table 1 Prevalence (\%) of symptoms and lung function abnormalities for smoking, objective dust, and subjective dust categories

\begin{tabular}{|c|c|c|c|c|c|c|c|c|c|c|}
\hline & \multirow[b]{2}{*}{$\begin{array}{l}\text { Total } \\
(n=224)\end{array}$} & \multicolumn{3}{|l|}{ Smoking } & \multicolumn{3}{|c|}{ Objective dust } & \multicolumn{3}{|c|}{ Subjective dust } \\
\hline & & $\begin{array}{l}\text { Never } \\
(n=32)\end{array}$ & $\begin{array}{l}E x- \\
(n=43)\end{array}$ & $\begin{array}{l}\text { Current } \\
(n=149)\end{array}$ & $\begin{array}{l}\text { Low } \\
(n=29)\end{array}$ & $\begin{array}{l}\text { Medium } \\
(n=149)\end{array}$ & $\begin{array}{l}\text { High } \\
(n=44)\end{array}$ & $\begin{array}{l}\text { Low } \\
(n=52)\end{array}$ & $\begin{array}{l}\text { Medium } \\
(n=112)\end{array}$ & $\begin{array}{l}\text { High } \\
(n=52)\end{array}$ \\
\hline \multicolumn{11}{|c|}{ Symptoms } \\
\hline \multicolumn{11}{|l|}{ Cough } \\
\hline on waking & $33 \cdot 9$ & $31 \cdot 3$ & $34 \cdot 9$ & $34 \cdot 5$ & $13 \cdot 8$ & $37 \cdot 6^{\star}$ & $34 \cdot 1$ & $17 \cdot 3$ & $35 \cdot 7^{\star}$ & $42 \cdot 3^{\star \star}$ \\
\hline day or night & $29 \cdot 9$ & $21 \cdot 9$ & $27 \cdot 9$ & $32 \cdot 6$ & $20 \cdot 7$ & 31.5 & $29 \cdot 5$ & $9 \cdot 6$ & $32 \cdot 1 \star \star$ & $42 \cdot 3^{\star \star \star}$ \\
\hline $\begin{array}{l}\text { Cough for three } \\
\text { months/y }\end{array}$ & $25 \cdot 4$ & $18 \cdot 8$ & & & 13.8 & $28 \cdot 7^{\star}$ & & & & \\
\hline Sputum & $28 \cdot 0$ & $\begin{array}{l}18 \cdot 8 \\
28 \cdot 1\end{array}$ & $\begin{array}{l}23.3 \\
14 \cdot 0\end{array}$ & $\begin{array}{l}28 \cdot 8 \\
33 \cdot 8\end{array}$ & $\begin{array}{l}13.8 \\
10.3\end{array}$ & $29 \cdot 3^{\star}$ & $36 \cdot 4^{\star}$ & $\begin{array}{l}9 \cdot 6 \\
7 \cdot 7\end{array}$ & $\begin{array}{l}25 \cdot 0 \pi \star \\
28 \cdot 6^{\star \star}\end{array}$ & $43 \cdot 4^{\star \star \star \star}$ \\
\hline \multicolumn{11}{|c|}{ Sputum for three months/y: } \\
\hline Previous year & $17 \cdot 9$ & 12.5 & $14 \cdot 0$ & $20 \cdot 9$ & $10 \cdot 7$ & $19 \cdot 3$ & $18 \cdot 2$ & 1.9 & $16 \cdot 1^{\star \star}$ & $34 \cdot 0^{\star \star}$ \\
\hline$>$ one year & $22 \cdot 8$ & $25 \cdot 0$ & $16 \cdot 3$ & $25 \cdot 2$ & $10 \cdot 3$ & 25.5 & $22 \cdot 7$ & $3 \cdot 8$ & $25 \cdot 0^{\star \star}$ & $32 \cdot 7 \star \star \star$ \\
\hline$>$ three years & $14 \cdot 7$ & 18.8 & $9 \cdot 3$ & $15 \cdot 8$ & 6.9 & $16 \cdot 7$ & 13.6 & 3.8 & $17 \cdot 0^{\star}$ & $18 \cdot 9^{\star}$ \\
\hline Dyspnoea & $19 \cdot 2$ & $15 \cdot 6$ & $16 \cdot 3$ & $21 \cdot 7$ & 13.8 & $18 \cdot 1$ & $25 \cdot 0$ & 5.8 & $20 \cdot 7^{\star}$ & $28 \cdot 3^{\star \star}$ \\
\hline Tight chest & $23 \cdot 2$ & $28 \cdot 1$ & $11 \cdot 6$ & 25.9 & $20 \cdot 7$ & 20.8 & $31 \cdot 8$ & $7 \cdot 7$ & $22 \cdot 3^{\star}$ & $40 \cdot 4^{\star \star \star}$ \\
\hline Wheeze & $32 \cdot 1$ & $15 \cdot 6$ & $27 \cdot 9$ & $38 \cdot 1^{\star}$ & $24 \cdot 1$ & $32 \cdot 9$ & $34 \cdot 1$ & $7 \cdot 7$ & $33 \cdot 9^{\star \star}$ & $48 \cdot 1^{\star \star \star}$ \\
\hline \multicolumn{11}{|l|}{ Wheeze and short } \\
\hline of breath & $15 \cdot 6$ & $15 \cdot 6$ & $11 \cdot 6$ & $16 \cdot 5$ & $10 \cdot 3$ & $16 \cdot 1$ & $15 \cdot 9$ & 1.9 & $19 \cdot 6^{\star \star}$ & $19 \cdot 2^{\star \star \star}$ \\
\hline \multicolumn{11}{|c|}{ Previous treatment for: } \\
\hline Bronchitis & $12 \cdot 2$ & $6 \cdot 3$ & $7 \cdot 0$ & $15 \cdot 3$ & $13 \cdot 8$ & $10 \cdot 9$ & $13 \cdot 6$ & $11 \cdot 8$ & $10 \cdot 8$ & $17 \cdot 3$ \\
\hline Pneumonia & $12 \cdot 2$ & $3 \cdot 1$ & $14 \cdot 0$ & $13 \cdot 1$ & $20 \cdot 7$ & $10 \cdot 9$ & 11.4 & 5.9 & $14 \cdot 4$ & $9 \cdot 6$ \\
\hline Tuberculosis & $7 \cdot 6$ & 0.0 & 11.6 & 8.8 & $3 \cdot 4$ & $5 \cdot 4$ & $18 \cdot 2$ & 0.0 & $6 \cdot 3$ & $17 \cdot 3^{\star}$ \\
\hline Asthma & $6 \cdot 7$ & 0.0 & $4 \cdot 7$ & 9.5 & 6.9 & $6 \cdot 1$ & $9 \cdot 1$ & 1.9 & $6 \cdot 3$ & $13 \cdot 5^{\star}$ \\
\hline \multicolumn{11}{|c|}{ Ever suffered from: } \\
\hline Rhinitis & $18 \cdot 8$ & 21.9 & $16 \cdot 3$ & $19 \cdot 7$ & $10 \cdot 3$ & 14.9 & $36 \cdot 4^{\star}$ & $7 \cdot 7$ & $18 \cdot 0$ & $28 \cdot 8^{\star \star}$ \\
\hline Watery eyes & 18.9 & $15 \cdot 6$ & $9 \cdot 3$ & 23.5 & 6.9 & $20 \cdot 3$ & $20 \cdot 9$ & $3 \cdot 8$ & $20 \cdot 7^{\star \star}$ & $25 \cdot 5^{\star \star}$ \\
\hline Hayfever & $6 \cdot 3$ & 0.0 & $7 \cdot 0$ & 1.6 & 0.0 & $4 \cdot 7$ & 0.0 & 0.0 & 0.9 & $4 \cdot 0$ \\
\hline Skin rashes & $24 \cdot 2$ & 21.9 & $23 \cdot 3$ & $24 \cdot 8$ & $24 \cdot 1$ & $22 \cdot 3$ & $31 \cdot 8$ & $15 \cdot 4$ & $24 \cdot 3$ & $28 \cdot 8$ \\
\hline \multicolumn{11}{|c|}{ Abnormalities of lung function } \\
\hline $\mathrm{FEV}_{1} / \mathrm{FVC}<70 \%$ & $14 \cdot 0$ & $3 \cdot 1$ & $16 \cdot 7$ & $15 \cdot 8$ & $13 \cdot 8$ & $14 \cdot 8$ & $11 \cdot 4$ & 3.9 & $14 \cdot 5$ & $24 \cdot 5^{\star}$ \\
\hline \multicolumn{9}{|c|}{ FEV, decrease Monday-Thursday } & 7.0 & (0.0 \\
\hline \multicolumn{11}{|c|}{$\begin{array}{c}>5 \% \\
\text { Increase in } \mathrm{FEV}_{1} \text {, on rimiterol: }\end{array}$} \\
\hline$>5 \%$ & $26 \cdot 6$ & $12 \cdot 5$ & $20 \cdot 5$ & $32 \cdot 5^{\star}$ & $27 \cdot 6$ & $23 \cdot 1$ & $37 \cdot 5$ & $15 \cdot 6$ & $32 \cdot 7^{\star}$ & $24 \cdot 0$ \\
\hline$>10 \%$ & $10 \cdot 8$ & $6 \cdot 3$ & $7 \cdot 7$ & 13.0 & $10 \cdot 3$ & $9 \cdot 7$ & $15 \cdot 0$ & 6.7 & 11.9 & $12 \cdot 0$ \\
\hline
\end{tabular}

Prevalence significantly greater than respective never smoked or low dust category on $\chi^{2}$ test in $2 \times 2$ tables; ${ }^{\star} p<0.05$; ${ }^{\star \star} p<0.01$; $\star \star \star \mathrm{p}<0.001$.

providing an index of cumulative dust dose during employment at the mill. Dust measurement allowed each worker to be allocated an objective category, a current dust score, and a cumulative dust dose for investigation of dose-response relations.

Statistical analysis was done with BMDP statistical software ${ }^{21}$ on a VAX mainframe computer. The distributions of duration of service and cumulative dust dose were highly skewed, and were transformed logarithmically before testing. Association between potentially hazardous exposures and respiratory outcomes was investigated by means of $\chi^{2}$ tests and multiple logistic regression for categorical outcomes, and analysis of variance and multiple linear regression for continuous outcomes.

\section{Results}

Most workers $(67 \%)$ were smokers at the time of the study. Of these, $53 \%$ smoked fewer than 10 cigarettes per day. Seventy six workers $(34 \%)$ had previously worked on South African mines. Two hundred and fifteen $(96 \%)$ were men. Most (160) were black, 52 were of mixed race, and 12 were white. The mean age of subjects was 42.7 with no significant difference in age between smoking or dust categories.

Table 1 compares the crude prevalences of symptoms and abnormalities in lung function for the different smoking, objective dust, and subjective dust categories. Prevalences of all symptoms, of previous tuberculosis, and of airflow limitation (defined as $\mathrm{FEV}_{1} / \mathrm{FVC}<70 \%$ ) were higher with ascending subjective dust categories. Linear tests for trend were also significant (not shown here). Many of these prevalences were also higher with ascending objective dust categories and were significantly higher for sputum, chronic cough, and rhinitis. Morning cough, chronic cough, and chronic sputum production were more frequent in the medium than the high objective dust category. Symptom prevalences were similar for the three smoking categories but the prevalence of wheeze was significantly higher in current smokers than in never smokers. Ex-smokers showed a confusing variation in prevalences.

Most subjects showed an increase in $\mathrm{FEV}_{1}$ from Monday to Thursday (mean increase $3.5 \%$ of Mon- 
Table 2 Dust in air concentrations $\left(\mathrm{mg} / \mathrm{m}^{3}\right)$ for exposure zones

\begin{tabular}{|c|c|c|c|c|c|}
\hline $\begin{array}{l}\text { Objective dust } \\
\text { category }\end{array}$ & Exposure zone & $\begin{array}{l}\text { No } \\
\text { exposed }\end{array}$ & $\begin{array}{l}\text { No } \\
\text { sampled }\end{array}$ & Mean (range) & $\begin{array}{l}\text { Dust } \\
\text { score } \dagger\end{array}$ \\
\hline $\begin{array}{l}\text { Low } \\
\text { Medium }\end{array}$ & $\begin{array}{l}\text { Office, laundry, canteen } \\
\text { Forklift and lorry drivers } \\
\text { Millers and silo and packing supervisors } \\
\text { Maintenance } \\
\text { Cleaners and sweepers } \\
\text { Bag handling } \\
\text { All medium zones } \\
\text { Shovel or pack grain }\end{array}$ & $\begin{array}{r}37 \\
24 \\
10 \\
9 \\
16 \\
74 \\
133 \\
54\end{array}$ & $\begin{array}{r}6 \\
8 \\
4 \\
4 \\
4 \\
11 \\
31 \\
13\end{array}$ & $\begin{array}{l}0.53(0.00-0.71) \\
1.16(0.10-4.35) \\
1.34(0.36-2 \cdot 41) \\
3.02(0.00-10 \cdot 71) \\
3.50(0.43-7 \cdot 70) \\
3.52(0.57-8.69) \\
2.89 \star(0.10-10 \cdot 71) \\
17.62(0.81-95 \cdot 59)\end{array}$ & $\begin{array}{l}0 \\
1 \\
1 \\
3 \\
3 \\
3\end{array}$ \\
\hline Total & & 224 & 50 & $6.10^{\star}(0.00-95.59)$ & \\
\hline
\end{tabular}

^Mean weighted by total workers in each zone.

+For estimates of current and cumulative exposure.

day value). Workers were characterised as having acute or reversible airway obstruction if their changes in FEV 1 were more pronounced than the rest of the study population. Cut off points were defined at levels providing sufficient power for analysisalthough the definitions may differ from clinical conventions, they are epidemiologically meaningful. The prevalence of acute airway obstruction, as shown by a decrease of $\mathrm{FEV}_{1}$ of at least $5 \%$ from Monday to Thursday, was $8.4 \%$ overall, this being significantly higher in never smokers than in current smokers, but not varying significantly between dust groups. Reversible airway obstruction, as shown by an increase of at least $10 \%$ after treatment with a bronchodilator on Thursday, was present in $10.8 \%$ of subjects, was higher among current smokers than never-smokers, and was higher with ascending dust categories, although not significantly so.

Of the $32 \%$ of subjects who reported wheezing, a proportion had evidence of the wheeze being work related: $36 \%$ noticed wheezing less on days not at work, $40 \%$ noticed wheezing worst after work, and $64 \%$ reported wheezing less on holidays than at work. The observation that wheezing improved on holidays was associated with an increase in $\mathrm{FEV}_{1}$ of at least $5 \%$ after a bronchodilator $\left(\chi^{2}=5 \cdot 10\right.$; $\mathrm{p}=0.024$ ).

Most workers were exposed to dust concentrations similar to or lower than those reported in other studies (table 2). ${ }^{15}$ In the high dust group, the mean exposure was far in excess of the American Conference of Governmental Hygienists' threshold limit value of $4 \mathrm{mg} / \mathrm{m}^{3}$. Wide variations in exposures were seen within exposure zones, but the order of the mean concentration of the zones was consistent with the authors' previous assessment.

Cross tabulation of the distribution of subjects in subjective and objective dust categories showed a consistency of only $54 \%$, with a slight bias of $5 \cdot 1 \%$ towards objective. Regression of subjective on objective dust categories gave an $R^{2}$ value of only $13 \cdot 1 \%$.

In initial multivariate analysis, pack-years were less strongly associated with respiratory outcomes than was smoking category. Ex-smokers were ex- cluded from the multivariate analyses reported here, because of the uncertainty in assessing their smoking exposure. Of the 224 subjects, 43 ex-smokers and three subjects whose spirometry traces were unacceptable were excluded from multivariate analysis. A further eight did not answer the question on dust exposure and 11 did not answer the questions on smoking. The remaining 159 subjects $(71 \%)$ were included in the multivariate analyses. Weight was not independently associated with exposure or outcomes and was not considered in further analysis.

Subjective dust and smoking categories were forced into the logistic regression equation (BMDPLR) as independent variables, producing odds ratios (ORs) with 95\% confidence intervals (95\% CIs) for symptoms and lung function abnormalities (table 3). Odds ratios for symptoms, improvement of symptoms on days not at work, and airflow limitation increased with ascending dust concentrations. Odds ratios for the high dust group were all significantly raised. No dust effect was shown for changes in $F_{E V}$ across the working week or after a bronchodilator. Current smokers had significantly raised ORs for wheeze and increase in $\mathrm{FEV}_{1}$ of $5 \%$ or greater after bronchodilator. These results show a significant association between subjective assessment of exposure to dust and symptoms and airflow limitation-a dose-response effect independent of smoking. This association is stronger than the independent association between smoking and most symptoms or airflow limitation.

When objective dust and smoking were forced into the regression equation as independent variables, ORs for most symptoms were also raised for medium and high dust groups, with the exception of dyspnoea. The lower $95 \%$ CI was only greater than one, however, for cough (OR $=1.83 ; 95 \% \mathrm{CI} 1.01-3.32)$ and sputum $(\mathrm{OR}=2.31 ; 95 \% \mathrm{CI} 1 \cdot 17-4.57)$, and the ORs did not show the same gradient as they did when subjective dust and smoking were used. Current smokers had a significantly raised odds ratio for wheezing $(\mathrm{OR}=1.82 ; 95 \% \mathrm{CI} 1 \cdot 14-2.91)$ and for $5 \%$ response of $\mathrm{FEV}_{1}$ to bronchodilator $(\mathrm{OR}=1.59$; $95 \%$ CI 0.99-1.36). Thus the independent effect of 
Table 3 Odds ratios of symptoms and spirometric abnormalities for different smoking and subjective dust categories compared with respective never smoked and low dust categories (logistic regression model)

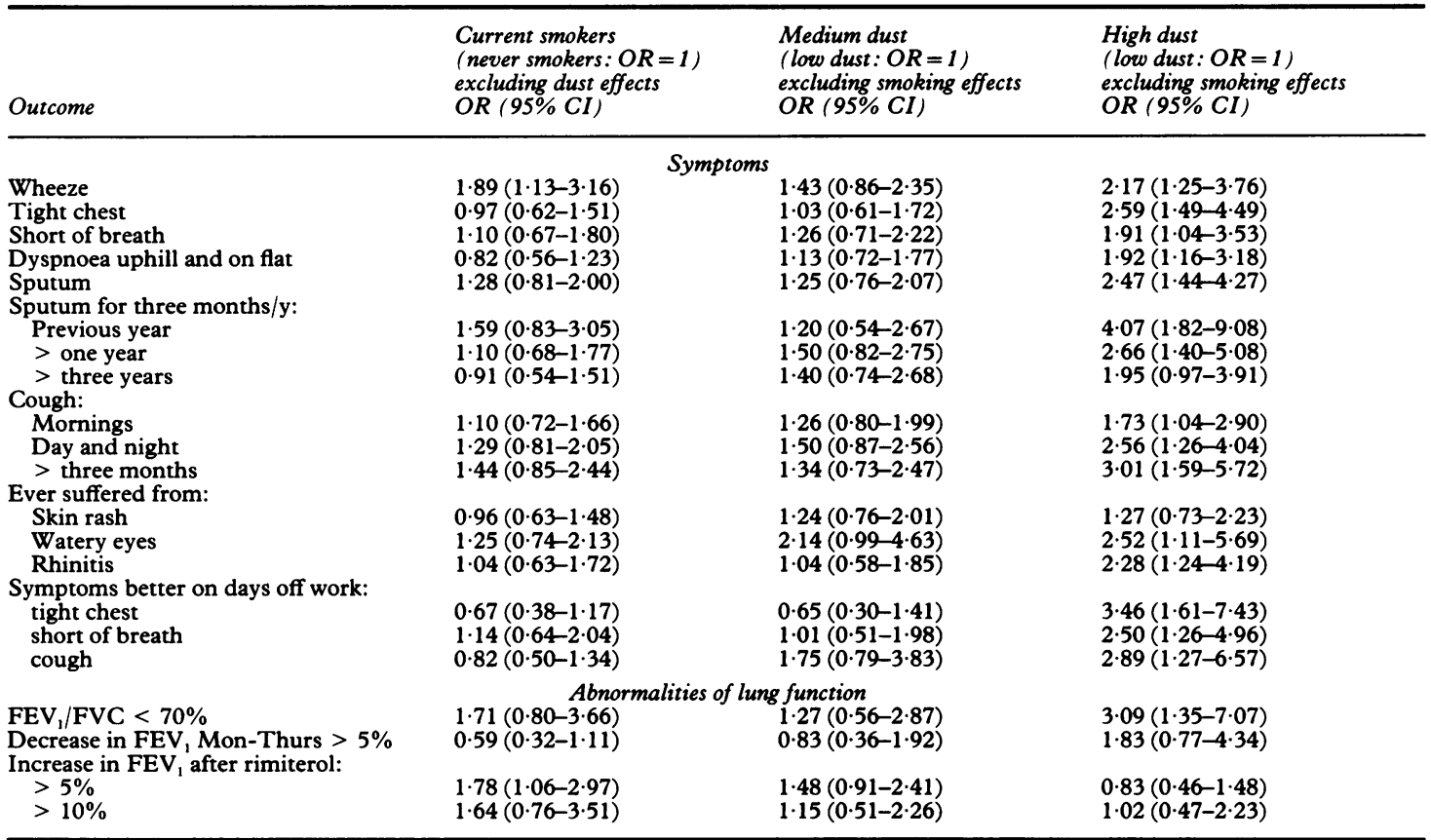

objective dust category on most symptoms or abnormalities of lung function was not as great as the effect of subjective dust category, confirming the trend in crude prevalences (table 1).

Stepwise logistic regression was performed with symptoms or spirometric abnormalities as outcomes, and smoking category, subjective dust category, objective dust category, age, duration of service, and cumulative dust dose as possible independent variables.

Subjective dust category was associated with all symptoms and with airflow limitation (improvement $\chi^{2}$ on entry of variable into the equation at $p$ levels $<0.05$ ). The $\log$ of cumulative dust dose was associated with sputum production $(p=0.001)$. Smoking category was associated with wheeze $(p<0.001)$. These results support the finding that symptoms and airflow limitation are most strongly associated with subjective dust category. However, cumulative dust exposure was selected in preference to subjective dust or age as a predictor of sputum production.

Stepwise logistic regression was performed with symptoms as outcomes and the following continuous variables as possible independent variables: $\mathrm{FEV}_{1} /$ $\mathrm{FVC} \%, \mathrm{FEV}_{1}$ change across the week, $\mathrm{FEV}_{1}$ increase after bronchodilator, FEV $_{1}$, and FVC. The FEV 1 FVC $\%$ or FEV, were selected as having a significant negative association with all symptoms (improvement $\chi^{2}$ on entry at $p$ levels $<0.05$ ). As declines in these two variables indicate airway obstruction, an association between airway obstruction and respiratory symptoms was shown.

The results of the 1989 survey were compared with those of the 1983 survey conducted in the same mill. One hundred and two of the 154 workers surveyed in $1983(67 \%)$ were included in the 1989 study, and were studied separately. The prevalences of symptoms in 1983 were compared between workers who remained working at the mill ("stayers"), and those who left the mill between 1983 and 1989 ("leavers") (table 4). Prevalences of all symptoms were higher among those who left than among those who remained at the mill. The prevalence differences were not significant, however, because they were slight and the numbers were small. No differences in lung functions were noted between "leavers" and "stayers".

The prevalence of symptoms among workers included in both studies increased slightly from 1983 to 1989 . When only those subjects who did not change dust or smoking exposures were considered, no associations were found between changes in symptom frequencies and smoking or dust category. The category of dust exposure reported in 1983 was not associated with the probability of leaving work thereafter.

Comparison of lung functions between 1983 and 1989 showed that $\mathrm{FEV}_{1}$ values increased by a mean of $248 \mathrm{ml}$ (standard deviation (SD) $380 \mathrm{ml}$ ), and FVC 
Table 4 Prevalence (\%) of symptoms, past illnesses, and airway reaction in 1983 of workers who subsequently left or remained in employment

\begin{tabular}{|c|c|c|}
\hline $\begin{array}{l}\text { Symptom or } \\
\text { lung function change }\end{array}$ & $\begin{array}{l}\text { Left } \\
(n=52)\end{array}$ & $\begin{array}{l}\text { Stayed } \\
(n=102)\end{array}$ \\
\hline \multicolumn{3}{|l|}{ Cough: } \\
\hline $\begin{array}{l}\text { Mornings } \\
\text { Day and night } \\
\text { three months/y }\end{array}$ & $\begin{array}{l}59 \cdot 6 \\
44 \cdot 9 \\
53 \cdot 8\end{array}$ & $\begin{array}{l}46 \cdot 1 \\
39 \cdot 2 \\
39 \cdot 2\end{array}$ \\
\hline \multicolumn{3}{|l|}{ Sputum production: } \\
\hline $\begin{array}{l}\text { Usually } \\
\text { three months/y }\end{array}$ & $42 \cdot 3$ & $37 \cdot 9$ \\
\hline $\begin{array}{l}\text { previous year } \\
>\text { one year }\end{array}$ & $\begin{array}{l}34.0 \\
26.9\end{array}$ & $\begin{array}{l}25 \cdot 5 \\
20 \cdot 4\end{array}$ \\
\hline$>$ three years & $17 \cdot 3$ & 13.6 \\
\hline $\begin{array}{l}\text { Dyspnoea } \\
\text { Dyspnoea > peers } \\
\text { Tight chest }\end{array}$ & $\begin{array}{l}21 \cdot 2 \\
18 \cdot 6 \\
30 \cdot 8\end{array}$ & $\begin{array}{r}11 \cdot 7 \\
8 \cdot 8 \\
18 \cdot 4\end{array}$ \\
\hline Wheeze & $28 \cdot 8$ & $19 \cdot 4$ \\
\hline $\begin{array}{l}\text { Wheeze and dyspnoea } \\
\text { Previous treatment for: }\end{array}$ & $7 \cdot 1$ & $1 \cdot 1$ \\
\hline \multicolumn{3}{|l|}{ Previous treatment for: } \\
\hline $\begin{array}{l}\text { Bronchitis } \\
\text { Asthma }\end{array}$ & 11.5 & $7 \cdot 8$ \\
\hline $\begin{array}{l}\text { Asthma } \\
\text { Pneumonia }\end{array}$ & $\begin{array}{l}5 \cdot 8 \\
9 \cdot 6\end{array}$ & $\begin{array}{l}3 \cdot 9 \\
5 \cdot 9\end{array}$ \\
\hline $\begin{array}{l}\text { Increase in } \mathrm{FEV}_{1}>5 \% \text { after } \\
\text { bronchodilator }\end{array}$ & $45 \cdot 0$ & $34 \cdot 0$ \\
\hline
\end{tabular}

decreased slightly by a mean of $28 \mathrm{ml}$ (SD $463 \mathrm{ml}$ ). The increase in FEV 1 was not physiologically plausible, and was ascribed to the differences in spirometers used on the two occasions.

\section{Discussion}

Findings were essentially similar in this cross sectional study to the 1983 study and to other reports. ${ }^{1-5}$ Subjects had higher prevalences of most symptoms than workers in other dusty South African industries, ${ }^{22}$ but similar patterns of symptoms to grain workers in North American studies. ${ }^{1}$ The predominant association with abnormal outcomes was dust exposure, which remained even after controlling for smoking.

Exposure to higher subjective dust concentrations increased the likelihood of airflow limitation but no dose-response effect of dust on acute changes in lung function was shown. The last finding may suggest a survivor effect. This is supported by the observation that the mean duration of service in the highest objective dust category was 11.4 years, compared with a mean of 5.9 years in the low dust category $(t=2.67 ; p=0.008)$. Workers in the high dust group may be "dust-resistant survivors", symptomatic workers having been selected out of dusty jobs at an early stage. This could constitute a healthy worker effect, reducing the association between dust and some abnormal outcomes. The consistent difference in prevalences of symptoms in the previous survey between subsequent "leavers" and "stayers" suggests that symptomatic workers are more likely to leave grain work, and is also supportive evidence of a healthy worker effect. The discrepancy between this study and others, which have shown associations between across shift declines in $\mathrm{FEV}_{1}$ and dust exposure, ${ }^{2}$ could be due to a stronger selection effect operating in this population, owing to less access to health care and easier replacement of affected workers. Alternatively across week reactions to dust may be less sensitive indices than across shift changes.

Subjective and objective dust categories were poorly correlated, partly due to the arbitrary divisions used. The greater effect of subjective dust measures on symptoms and airflow limitation, in comparison with objective dust measures, may be explained in one of two ways. Measuring actual exposure is exceedingly difficult in a grain mill due to the complex composition of the dust, a wide range of individual exposures within groups of workers performing similar tasks, and the difficulty in developing integrated representative real time measurements. Grain mills include a wide variety of milling and packing operations producing a range of products such as wheat bran, cake flour, and self raising flour, with varied milling and packing operations; thus exposures are more complex than in grain elevators, where most studies have been conducted. Workers may be able to assess their own exposure to dust better than a dust survey. Thus objective categorisation of exposure to dust may result in more nondifferential misclassification than workers' subjective impressions, with a consequent weakening of associations. Alternatively, workers who experience symptoms may be more likely to describe their work as dusty than asymptomatic workers with the same exposures, thereby introducing biases that falsely strengthen associations. These two explanations can only be adequately tested by exhaustive dust measurements that would account for all within and between variations in exposure.

The independent effects of smoking were generally less than the effects of dust, even though $47 \%$ of smokers smoked more than 10 cigarettes each day. The increased likelihoods among smokers of wheezing and of an increase in $\mathrm{FEV}_{1}$ of at least $5 \%$ after a bronchodilator, however, indicate that smoking is associated with reversible airflow obstruction. The observation that current smokers were less likely to experience a decrease in $\mathrm{FEV}_{1}$ across the week could be explained by the presence of some previous obstruction at the start of the week.

Most grain studies have compared grain workers with external controls. This survey, like the two previous South African studies, ${ }^{45}$ used three levels of exposure within the same workplace, which has the advantages of eliminating external selection factors and showing a gradient of effect with increasing dust categories. A disadvantage of this approach is that the low dust group was small, which, together with the healthy worker effect, may have decreased the significance of some comparisons. Also, workers in the 
low dust category may have been exposed to enough dust to affect respiratory health in some of them.

The study provides further evidence that grain dust causes a range of respiratory symptoms, including wheeze, chest tightness, dyspnoea, chronic sputum production, and chronic cough, as well as chronic airflow limitation. Spirometric evidence of acute airway obstruction was present in few workers, considering that grain dust is a recognised cause of occupational asthma. ${ }^{23}$ This finding may be due to the early departure of asthmatic workers from the industry; a longitudinal study with follow up of work leavers is still a priority for future research into grain dust and asthma. Stopping smoking would benefit the respiratory health of grain workers, but control of exposure to dust continues to be an important priority.

We are grateful to the Food and Allied Workers' Union for their continued interest and support; to the mill management for permission to conduct the survey, and for financial and logistic assistance; to $M$ Qotole and A Mia for interviewing and spirometry, D Edwards for spirometry, $P$ Lewis for assistance with the dust survey, Z Fuphe for data entry; to D Yach, S Louw, $N$ White, J Mets, and members of the Industrial Health Research Group for comments on the protocol and manuscript; and to $\mathrm{N}$ White for clinical evaluation of suspected asthma cases identified during the survey.

Requests for reprints to: Dr O M Bachmann, Department of Community Health, Medical School, University of Cape Town, Observatory 7925, South Africa.

1 Brown MA. Health hazards of storing, handling and shipping grain. NIOH and NIOSH basis for an occupational health standard. Cincinnati: National Institute of Occupational Safety and Health, 1988:11-29.

2 Chan-Yeung M, Enarson D, Grzybowski S. Grain dust and respiratory health. Can Med Assoc J 1985;133:969-73.

3 Warren CPW. Health and safety in the grain industry. In: Rom WN, ed. Environmental and occupational medicine. Boston: Little, Brown, 1983:221-32.
4 Yach D, Myers J, Bradshaw D, Benatar SR. A respiratory epidemiologic survey of grain mill workers in Cape Town, South Africa. Am Rev Respir Dis 1985;131:505-10.

5 Fonn S, Groeneveld H, DeBeer M, Becklake MR. Subjective and objective assessment of exposure to grain dust in relation to lung function change over a working week. In: Hogstedt C, Reuterwall C, eds. Progress in occupational epidemiology. Amsterdam: Elsevier, 1988:271-5.

6 Chan-Yeung M, Schulzer M, Maclean M, et al. A follow-up study of the grain workers in the port of Vancouver. Arch Environ Health 1981;36:75-81.

7 Tabona M, Chan-Yeung M, Enarson E, MacLean L, Dorken E, Schultzer M. Host factors affecting longitudinal decline in lung spirometry among grain elevator workers. Chest 1984;85: $782-6$.

8 Enarson D, Vedal S, Chan-Yeung M. Rapid decline in FEV in grain handlers. Relation to level of dust exposure. $\mathrm{Am} \mathrm{Rev}$ Respir Dis 1985;132:814-7.

9 Broder I, Corey P, Davies G, et al. Longitudinal study of grain elevator and control workers with demonstration of the healthy worker effect. J Occup Med 1985;27:873-80.

10 Broder I, Hutcheon MA, Mintz S, et al. Changes in respiratory variables of grain handlers and civic workers during their initial months of employment. Br J Ind Med 1984;41:94-9.

11 Robinson $S$. South African millers ready for possible deregulation. World Grain 1989;October:8-12.

12 Ferris BG. Epidemiology standardisation project. Am Rev Respir Dis 1978;118:7-53.

13 Gardner RM, Hankinson JL, Clausen JL, Crapo RO, Johnson RL, Epler GR. Standardisation of spirometry-1987 update. Am Rev Respir Dis 1987;136:1285-98.

14 Eisen EA, Robins JL, Greaves IA, Wegman DH. Selection effects of repeatability criteria applied to lung spirometry. $\mathrm{Am} \mathrm{J}$ Epidemiol 1984;120:734-42.

15 Gardner RM, Hankinson JL, West BJ. Evaluating commercially available spirometers. Am Rev Respir Dis 1980;121:73-82.

16 Vitallograph Limited. $S$-model spirometer. Operating and service manual. Buckingham: Vitallograph, 1982.

17 Myers J. Differential ethnic standards for lung functions or one standard for all? $S$ Afr Med J 1984;65:768-72.

18 Corn M, Esmen NA. Workplace exposure zones for classification of employee exposures to physical and chemical agents. $\mathrm{Am}$ Ind Hyg Assoc J 1979;40:47-57.

19 Leidel NA, Busch KA, Lynch JR. Occupational exposure sampling strategy manual. Washington, DC: US Government Printing Office, 1977, 72.

20 Eller PM, ed. NIOSH manual of analytical methods, 3rd ed. vol 1. Washington, DC: US Government Printing Office, 1984;0500:1-3.

21 Dixon WJ. BMDP statistical package. Los Angeles, California: University of California, 1985.

22 Myers JE, Cornell JE. Respiratory health of brickworkers in Cape Town, South Africa. Symptoms, signs and pulmonary function abnormalities. Scand J Work Environ Health 1989; 15:188-94.

23 Chan-Yeung M, Lam S. Occupational asthma. Am Rev Respir Dis 1986;13:686-703.

Accepted 18 February 1991 